\title{
Impact of Synectic Learning Model with Mind Mapping Assignment in Improving Student's Learning Outcomes and Cognitive Ability at Lab School Junior High School Palu
}

\author{
Kamaluddin \\ Universitas Tadulako \\ Palu, Indonesia \\ Darsikin \\ Universitas Tadulako \\ Palu, Indonesia
}

\author{
Amiruddin Kade \\ Universitas Tadulako, \\ Palu, Indonesia
}

\begin{abstract}
The purpose of this research is to acquire a review of the effectivity of synectic learning model with mind mapping assignment for improvement of learning outcomes in cognitive field for VIII grade students in Labschool Junior high school, Tadulako University, Palu. The pre-experimental with one-group pretest-posttest design method is used as the research method. The object of this research is students in VIII grade of Labschool junior high school, Tadulako University, Palu. Since there is only one class of VIII grade in this school, the population of the research also becomes the sample. The data is collected using a test that aims to identify the learning outcomes of students cognitive ability, and observation sheet to observe the learning achievement. Improvement data of cognitive learning outcome were analyzed with statistical software, SPSS for Windows version 16.0. The results of observation achievement of the learning model from teacher activity are $99,58 \%$ and $93,24 \%$ from student activity. The result of this observation shows that the synectic learning activities with mind mapping assignment almost done as a whole, both in teacher and students activities perspective. The percentage of the initial test mean score (pretest) for students cognitive abilities before learning process (pre-test) is $\mathbf{2 1 , 7 8 \%}$ from the ideal score, and then increase until $\mathbf{7 1 , 6 8 \%}$ after cognitive learning process with post-test. The significance of the percentage increase in the mean score of pre-test and posttest can be represented by gains normalized mean score $\langle$ g $\rangle$ for the cognitive achievement of students at $63.43 \%$ which can be categorized as a high result. These results show that the students cognitive abilities were high. The obtained results indicate that the application of synectic learning model with mind mapping assignment can increase cognitive abilities
\end{abstract}

Keywords- synectic learning model; mind mapping assignment; cognitive abilities

\section{INTRODUCTION}

The results of cognitive learning for students is an important thing in the learning process. It is based on these results reflect the level of students' intellectual abilities. Therefore, the learning process of physics must be built so that it can accommodate cognitive of student learning outcomes. However, the reality in the field, learning of physics is still not maximized in facilitating cognitive learning outcomes of students. The results of cognitive learning for students is an important thing in the learning process. It is based on these results reflect the level of students' intellectual abilities. Therefore, the learning process of physics must be built so that it can accommodate cognitive student learning outcomes. However, the reality in the field, learning of physics is still not maximized in facilitating cognitive learning outcomes of students.

Low achievement of cognitive allegedly linked to the learning process is not yet fully trained capabilities that exist in the realm of knowledge (cognitive). This is evidenced by the results of observations in the classroom which showed that the learning process carried out more on the transfer of knowledge with a lecture in the classroom, and the exercises as a reinforcement of the concept. The process of learning physics is also more done with explanations formulas. In fact, the formulas in physics is merely a consequence of the simplification of the statement of phenomena and processes that occur in nature. How the presentation of existing learning field like this causes important concepts in physics that should encourage students to think more deeply is lost, it can even cause misconceptions or misconceptions.

According to [1], one among the learning model that can influence the quality of student learning is the learning model application synectic. Although according to the research on a synectic learning model states that teaching synectic students with models are not easy, it takes the proper infrastructure to facilitate business activity as a synectic analogy. One of the infrastructures that have a relatively similar way of working with synectic learning model is the use of mind mapping. Ref. [2] stated that mind mapping is a way to organize and present concepts, ideas, tasks or other information in the form of a diagram. Mind mapping is generally present information that is connected to the central topic, in the form of keywords, images (symbols), and color so that one can learn and remember information quickly and efficiently. 
Based on the above description it appears there have in common synectic learning model and mind mapping by using the association of ideas to solve the problem. The similarity between the synectic learning model and mind mapping is exactly the reason researchers combined synectic learning model with mind mapping assignment.

Based on the above description shows that the synectic learning model and mind mapping has the potential to improve cognitive abilities of students. Therefore, this research problem formulation is: "How does the application of synectic learning model with mind mapping assignment to increase students' cognitive abilities?". This study aims Increased the cognitive ability of students to use synectic learning model with mind mapping assignment.

\section{METHODS}

In this study will be used methods are a pre-experimental method and descriptive method. The pre-experimental method used to observe the effect of the application of synectic learning model with mind mapping assignment to the student's cognitive abilities, and the descriptive method is used to describe the implementation of classroom learning with models that get synectic with mind mapping assignment. The design study is to determine the increase students' cognitive abilities is to design one group pretest-posttest design illustrated in table I.

TABLE I. DESIGN RESEARCH

\begin{tabular}{|c|c|c|}
\hline Pretest & $\begin{array}{c}\text { Independent Variable } \\
\text { (Treatment) }\end{array}$ & Posttest \\
\hline $\mathrm{Y}$ & $\mathrm{X}$ & $\mathrm{Y}$ \\
\hline \multicolumn{2}{|r}{} & a. (Frankel \& Wallen, 2007)
\end{tabular}

Information :

$\mathrm{Y}=$ pretest and posttest students' cognitive abilities

$\mathrm{X}=$ The treatments were synectic learning model with assignment of mind mapping

The research was conducted at SMP Labschool UNTAD Palu. The population in this study were all students of class VIII the second semester of 2016/2017 academic year consists of only one class. Therefore this study population as well as a sample. Data collection techniques in this research using observation sheet implementation of the model of learning, and the students' cognitive ability tests.

To see the percentage of achievement of learning implementation is determined from the average percentage for each activity. This value indicates the value of adherence to existing activities in synectic learning with mind mapping assignment. Data improvement of cognitive learning outcomes were analyzed with a statistical test to calculate the gain normalized score (N-Gain) from the initial test and the final test.

\section{RESULTS AND DISCUSSIONS}

This section will present the research results obtained along with a discussion of the application of learning models synectic with mind mapping assignment. The research was conducted from 12 October 2016 and ended on 4 November 20165 times face to face meetings.

Description of the implementation of the synectic learning model with the assignment of mind mapping can be seen from the implementation of learning. Implementation of Learning Implementation Plan (RPP) for ongoing learning activities observed by two observers each meeting.

The observations made by the observer is written in the format of observations that have been available, namely the implementation of the observation format of learning procedure. Based on observations obtained, that appropriate measures synectic learning with mind mapping assignments held by teachers of $99.58 \%$ based on the observation while learning model implementation is seen from the student activity gained an average of $93.24 \%$. The results of these observations show that the learning activities synectic with mind mapping assignments designed almost done as a whole, both teachers and students activities.

Cognitive abilities of students in this study were measured by using a form of essay test as many as 14 items that refer to indicators related learning material pressure.

Cognitive abilities measured the ability of the aspects given (C1), understanding (C2), and applying (C3). Measured dimensions of knowledge that is the factual knowledge (K1) and conceptual knowledge (K2).

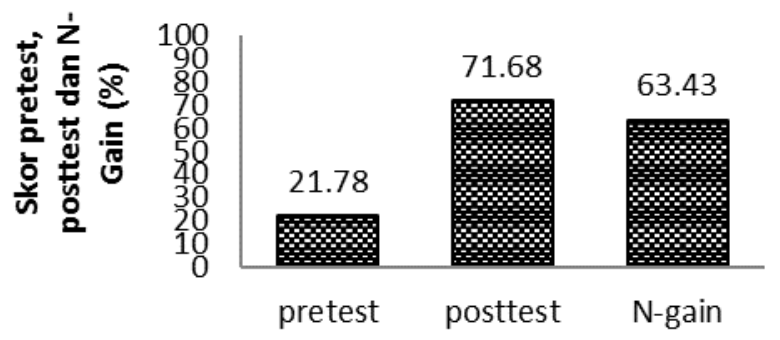

Fig. 1. Diagram Acquisition Score average pretest, posttest, and N-Gain Cognitive Ability Students

Figure 1 shows the average score of the initial test (pretest), the average score of the final test (posttest), and the average score of the gain is normalized $\langle\mathrm{g}\rangle$ cognitive learning outcomes are achieved by students after synectic learning model applied to the assignment of mind mapping, The percentage of mean score of the initial test (pretest) students' cognitive abilities before learning of $21.78 \%$ from the ideal score and the percentage of the final test scores (posttest) cognitive learning outcomes of students after learning $71.68 \%$ of the ideal score. The significance of the increase in the percentage of pretest and posttest mean score may be represented by the mean score of the gain normalized. From this data it obtained an average score gain normalized $\langle\mathrm{g}\rangle$ cognitive learning outcomes of students by $63.43 \%$. If confirmed in the category of Hake (1999), the result of the increase in the high category. This suggests that cognitive abilities of students on the concept of increased pressure by the high category in the application of synectic learning model with mind mapping assignment. 
Cognitive abilities in each sub-concepts that were examined in this study and comparison of the mean score of $\mathrm{N}$ Gain cognitive abilities for each sub-concepts can be seen in Figure 2.

From Figure 2 shows that the acquisition means score Gain Normalized (N-Gain) students obtained the highest in subconcept of pressure on the number of solids $72.44 \%$ while the lowest value in the sub-concepts of students is the Law of Archimedes that is equal to $59.99 \%$.
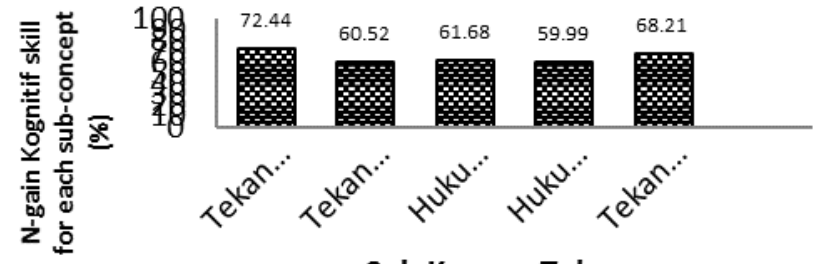

Sub Konsep Tekanan

Fig. 2. Comparison diagram of N-Gain average for cognitive skill for each sub-concept pressure

The Increase of cognitive abilities of students in every aspect of cognitive can be seen from the results of test scores obtained by students on each item are given the initial test and final test. Three cognitive aspects covered by the concept of pressure is: given (C1), understanding (C2), and apply (C3). For a comparison of the acquisition of cognitive learning outcome of students to each cognitive aspect can be seen in Figure 3.

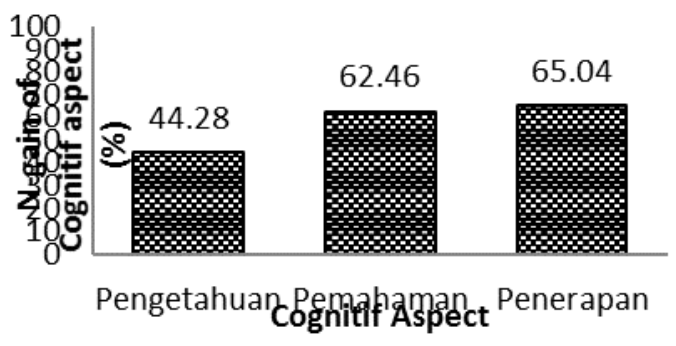

Fig. 3. Comparison Diagram for the Average N-Gain $\langle\mathrm{g}\rangle$ score for each cognitive aspect.

From the diagram above, it can be seen that the highest average score of $\mathrm{N}$-Gain cognitive achievement in every aspect of students obtained on application aspect (C3) amounted to $65.04 \%$, the category being found in understanding aspects (C2) of $62.45 \%$, and the lowest is given for aspect (C1) which amount is $44.28 \%$.

There is two dimension of knowledge that contains in pressure concept, i.e actual knowledge (K1) and conceptual knowledge (K2), which the results can be seen in Figure 1.4.

Based on Figure 1.4, it can be seen that the highest average score of N-Gain cognitive abilities achieved in the dimensional conceptual knowledge that reach $64.43 \%$; while the average score of cognitive ability on the dimensions of factual knowledge magnitude is $44.29 \%$. Increased cognitive abilities of students on factual knowledge and conceptual dimensions in this study are in the medium category.

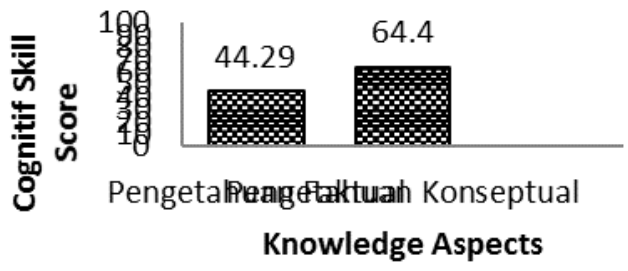

Fig. 4. Comparison diagram for the average of factual knowledge and conceptual knowledge for students cognitive skills

The results of the student pretest data analysis for the cognitive abilities indicate that the mean score before application of synectic learning models with mind mapping assignment is $38 \%$ of the ideal score. This result indicates that the students have a low cognitive ability. Posttest mean score of students' cognitive abilities after being given treatment achieved $64 \%$ of the ideal score, which in the medium category. The results also show that the highest cognitive abilities from the students are that there is no aspect of applying (C3) with a mean score of $0.65 \mathrm{~N}$-Gain with the category. It can occur since the student has understood concepts that they have learned.

In addition, aspects of the application (C3) is always practiced during the learning process, especially at the stage of identifying the core activities, the similarity between the concepts, analogies, and make a direct analogy. The increase in the given category $(\mathrm{C} 1)$ turned out to be the lowest of all when compared to other skills in aspects of cognitive ability that is 0.44 . The low mean score of $\mathrm{N}-$ Gain remembering aspects can be caused by not doing the pre-check of the ability to remember the topic in every meeting, for example through a quiz or assignment. This is not done caused by the lack of time left for learning takes place. The impact of not doing the precheck ability to remember at every meeting, the teacher can not know whether the implementation of learning has the maximum impact on the ability to remember or to other aspects of the ability of cognitive ability.

The increase of cognitive skill of the students caused by synectic learning method which concern in analogy task in the learning process which ended in a new understanding that more complex in a specific concept. Analogy as a method of synectic learning concept which stated as an activity to build imageries for a specific concept (new concept) for another concept (a concept that already understood) based on the equivalency between this two concept to achieve more complicated concept.

If it is evaluated based on the score that students achieved on every sub-concept of pressure, the highest result achieved in a concept about the solids that reach $72,44 \%$ from the ideal score, while the lowest score is in sub-concept of Archimedes Law, i.e 59,99\% from the ideal score. From interview to some students, it is understood that students feel easier understand the concept of solids rather than another concept since demonstration that given by the teacher is very easy to relate to the concept that they are learning. Besides, the example about the analogy that teacher gave much more easy to understand by the students rather than any other concepts. Students think that 
concept of Archimedian Law is the hardest concept to be understood. This is caused by the teacher explain the concept so fast about this concept, and also the analogy example is not easy to be understood.

Overall, synectic learning method with min mapping task can increase student cognitive study result, which is shown by the average of the N-Gain score from all aspect of cognitive aspect which in the model level category. The increase of cognitive skill caused by the synectic learning method with mind mapping tasks which facilitate the achievement of the meaning of the study. Sinektik learning method with mind mapping task is a learning process that had a purpose to accelerate interaction, activity, and students enthusiast in the learning process, so the student can accelerate their cognitive skill.

These findings match with research result by Vani (2012) which stated that the use of synectic learning method could accelerate the cognitive study result of students. Beside from implementation of this synectic learning method, in this research, the method also combined with the mind mapping tasks. Ref. [2] and [3] stated that implementation of mind mapping method could accelerate cognitive study results. Ref. [3] stated that information processing could increase. Ref. [3] stated that information processing which actualized in the form of mind mapping as an association of idea could trigger the improvement brain potential as maximal as it should be. [4] stated that the power of this synectic method with mind mapping in the form of improvement of cognitive skill is possible since both of this method have the same working scheme, i.e both of them use idea association to solve the problems. Another result stated that synectic learning method which combines with another method also could student study results.

\section{CONCLUSION}

According to the data and data analysis, we can conclude that implementation of synectic learning method with mind mapping task could improve the cognitive skill result for junior high school students.

Implementation of synectic learning method with mind mapping task needs a discipline in implementation in the class, related to time, in each step of the learning process, so the learning target could be achieved perfectly.

\section{REFERENCES}

[1] Suparno, P. Metodologi Pembelajaran Fisika. Yogyakarta: Universitas Sanata Dharma, 2009.

[2] Buzan, T, Buku Pintar Mind Map Untuk Anak. Jakarta: PT Gramedia Pustaka Utama, 2007.

[3] Ying, L (2014). The Effect Of Mind Mapping On Teaching And Learning : A Meta-Analysis. Beijing: School Of Educational Technology

[4] Khalifah, M.”Pengaruh Model Pembelajaran Sinektik Dipadu Dengan Mind Mapping Terhadap Kemampuan Berpikir Kreatif, Sikap Kreatif, Dan Penguasaan Materi'.Jakarta: Lentera Pendidikan, 2007. 